\title{
4A: Clinical pharmacological aspects of $H$. pylori treatment
}

\section{A:01 AZITHROMYCIN AND INCREASING DOSES OF OMEPRAZOLE FOR THE ERADICATION OF HELICOBACTER PYLORI}

M. Caselli ${ }^{1}$, M. Ruina ${ }^{1}$, L. Gallerani ${ }^{1}$, P. Fabbri ${ }^{1}$, P. Gaudenzi ${ }^{1}$, V. Alvisi ${ }^{1} .{ }^{i}$ School of Gastroenterology, University of Ferrara, Italy

Background: Helicobacter pylori is implicated in different gastroduodenal pathologies such as peptic disease and gastric cancer, and it is associated with ulcer relapse. This background makes the eradication of bacterial colonisation desirable in any clinical and endoscopical condition, also when associated with problems of mild entity. An effort should be made to make apt the eradication therapy to single problems.

Objectives: to evaluate the efficacy and tolerability of short term dual therapy with azithromycin and increasing doses of omeprazole.

Methods: two selected group of $50 \mathrm{H}$. pylori-positive patients matched for age, sex and race were compared for the prevalence of bacterial eradication rate after dual therapy with a standard dose of azithromycin (500 $\mathrm{mg} /$ day for 3 days) and increasing dose of omeprazole $(20 \mathrm{mg}$ b.i.d. or 40 $\mathrm{mg}$ b.i.d. for one week). $\mathrm{H}$. pylori presence before and after treatment was determined by urease test and histology.

Results: five-seven weeks after treatment, $\mathrm{H}$. pylori had been eradicated in 29 of 50 patients (58\%) who taken azithromycin and $40 \mathrm{mg} /$ day of umeprazole, and in 44 of 50 patients (88\%) who taken azithromycin in the same way and $80 \mathrm{mg} /$ day of omeprazole $(P=0.001)$.

Conclusions: short-term dual therapy with high dose of omeprazole combined with standard dose of azithromycin appears to have an high success eradication rate of $\mathrm{H}$. pylori colonisation, very good compliance and it appears to be without side-effects. Azithromycin seems to represent interesting antibiotic agent for future dual and triple therapy trials.

\section{A:02 THE ROLE OF $\mathrm{H}_{2}$-RECEPTOR ANTAGONIST IN THE ERADICATION OF H. PYLORI}

K.C. Yang, G.M. Wang, J.H. Chen, Y.H. Liu, Y.H. H., T.J. Chen ${ }^{1}$, S.C. Lee ${ }^{2}{ }^{1}$ Depts of Internal Medicine and Clinical Pathology, Shin Kong Wu Ho-Su Memorial Hospital, Taiwan, R.O.C.; ${ }^{2}$ Institute of Nuclear Energy Research, Taiwan, R.O.C.

Introduction: The addition of an antisecretory drug to anti-H. pylori (HP) regimens have been reported to increase eradication rates due to enhanced effectiveness of some antimicrobials. In contrast to proton pump inhibitors (PPI), however, $\mathrm{H}_{2}$-receptor antagonists $\left(\mathrm{H}_{2} \mathrm{RA}\right)$ have rarely been studied in combination with antimicrobials to eradicate $\mathrm{HP}$.

Aim: (1) To verify the efficacy of ranitidine in combination with amoxicillin and metronidazole for eradication of HP. (2) To elucidate the simplest and cost-effective amoxicillin dosage and duration of treatment.

Methods: 131 patients (95 males; 36 females, mean age \pm SE $45.2 \pm$ $1.0 \mathrm{yrs}$ ) with active DU and HP infection were enrolled in this prospective, randomized study. HP infection was confirmed by positive rapid urease test and presence of bacteria in modified Giemsa staining from antral biopsy. All the patients were randomly allocated to 4 groups of regimens (see below). Eradication was defined as negative results of rapid ureased test, modified Giemsa staining and 13C-UBT at least 4 weeks after the completion of therapy.

Results:

\begin{tabular}{lllll}
\hline Treatment/group & A & B & C & D \\
\hline Ranitidine bid & $300 \mathrm{mg}$ & $150 \mathrm{mg}$ & $150 \mathrm{mg}$ & $150 \mathrm{mg}$ \\
Amoxicillin qid & $500 \mathrm{mg}$ & $250 \mathrm{mg}$ & $500 \mathrm{mg}$ & $500 \mathrm{mg}$ \\
Metronidazole qid & & $250 \mathrm{mg}$ & $250 \mathrm{mg}$ & $250 \mathrm{mg}$ \\
Duration & 2 weeks & 2 weeks & 2 weeks & 1 week \\
HP eradication (\%) & $48 \% *$ & $90 \%$ & $85 \%$ & $77 \%$ \\
Side-effect (\%) & $19 \%$ & $15 \%$ & $20 \%$ & $18 \%$ \\
\hline
\end{tabular}

$* \mathrm{P}<0.05$

Conclusions: (1) Ranitidine is as effective as PPI in achieving high HP eradication rates in triple therapy. (2) Low dose amoxicillin (1 gm/day) in combination with ranitidine and metronidazole (RAM) is a very effective regimen for eradicating HP infection. (3) The efficacy of RAM decreases when treatment duration is shortened to one week. (4) Dual therapy with ranitidine plus amoxicillin is ineffective.
4A:03 COMPARISON OF OMEPRAZOLE AND CLARITHROMYCIN VERSUS OMEPRAZOLE, CLARTHROMYCIN AND METRONIDAZOLE IN THE TREATMENT OF HELICOBACTER PYLORI

R.A. Veenendaal ${ }^{1}$, J.M. Götz ${ }^{\text {}}$, J.L. Meijer ${ }^{2}$, I. Biemond ${ }^{1}$, A.T. Bernards ${ }^{3}$, G.J.A. Offerhaus, C.B.H.W. Lamers ${ }^{1} .{ }^{1}$ University Hospital Leiden, The Netherlands; ${ }^{2}$ Spaarne Hospital Heemstede, The Netherlands; ${ }^{3}$ Academic Medical Centre Amsterdam, The Netherlands

We investigated the efficacy of a high dose two week regimen consisting of Omeprazole (OM) and Clarithromycin (CLA) versus a combination of OM, CLA, and Metronidazole (MET) in the treatment of $H$. pylori. The efficacy of the two regimens was examined in a multicentre, double-blind, randomized study including 50 patients with $H$. pylori infection. $H$. pylori status was assessed before and eight weeks after treatment by culture (antrum and corpus) and histology (Sydney classification). All patients received OM $(20 \mathrm{mg})$ twice daily, CLA $(500 \mathrm{mg})$ thrice daily, and either placebo or MET $(500 \mathrm{mg})$ thrice daily for two weeks.

\begin{tabular}{lll}
\hline Treatment & Hp Eradication* & $95 \%$ CI \\
\hline OM, CLA & $16 / 25(64 \%)$ & $42.5-82$ \\
OM, CLA, MET & $24 / 25(96 \%)^{* *}$ & $80-100$ \\
\hline
\end{tabular}

*Intention to treat. ${ }^{* *} \mathrm{p}<0.01$, chi-square.

Two patients (one from both groups) were lost to follow up. No patients discontinued because of adverse events. Minor side effects, however, were common. Treatment failure (double therapy) was in a significant number of patients accompanied by CLA resistance post-treatment.

In conclusion, triple therapy (OM, CLA, MET) is superior to high dose double therapy (OM, CLA) in the treatment of $H$. pylori.

\section{A:04 CLINICAL AND ECONOMIC EFFECTS OF IMMEDIATE HELICOBACTER PYLORI ERADICATION FOR PATIENTS WITH DOCUMENTED PEPTIC ULCER DISEASE BUT UNKNOWN HELICOBACTER PYLORI STATUS}

A.M. Fendrick, J.T. McCort, B.S. Bloom ' . University of Michigan, Ann Arbor, Michigan; ' University of Pennsylvania, Philadelphia, Pennsylvania

Background: Nearly all persons with peptic ulcer disease who have not been treated for $H$. pylori infection experience an ulcer recurrence. Once $H$. pylori is eradicated, patients may no longer experience ulcer-related symptomatic relapses or need chronic acid suppression therapy. The costeffectiveness of a strategy of immediate eradication of $\boldsymbol{H}$. pylori for documented ulcer patients receiving maintenance antisecretory therapy and unknown $H$. pylori status has not been addressed.

Methods: A decision analytic model estimated the clinical and economic effects of treatment alternatives for asymptomatic patients with previously documented peptic ulcer but unknown $H$. pylori status receiving maintenance antisecretory therapy. Two management strategies were evaluated: Strategy 1 - immediate $H$. pylori eradication therapy and cessation of maintenance therapy; and Strategy 2 - continued maintenance antisecretory therapy with $H$. pylori eradication therapy reserved for those patients at first symptom recurrence.

Results: At one year the model estimated that a strategy of immediate $H$. pylori eradication therapy (Strategy 1) led to $22 \%$ fewer months with ulcers (28.7 vs. 36.8 ulcer months/100 patient years), $10 \%$ fewer months with ulcer symptoms (21.0 vs. 23.1 ), and $24 \%$ lower per-patent expenditures (\$587 vs. $\$ 767 /$ per patient year) than a strategy of maintenance antisecretory therapy (Strategy 2). Immediate $H$. pylori eradication therapy resulted in $14 \%$ more months with symptoms from all causes ( 37.9 vs. $33.2 /$ symptom months/100 patient years) than Strategy 2, because maintenance antisecretory therapy was effective in treating symptoms from causes other than peptic ulcer disease.

Conclusions: Ulcer-related outcomes for patients receiving maintenance antisecretory agents for documented peptic ulcer disease can be improved at reduced direct medical cost with the prompt eradication of $H$. pylori infection. 


\section{A:05 A THREE-DAY COURSE OF INTRAVENOUS OMEPRAZOLE PLUS ANTIBIOTICS FOR H. PYLORI-POSITIVE BLEEDING DUODENAL ULCER}

Bor-Shyang Sheu, Hsiao-Bai Yang, Ih-Jen Su, Xi-Zhang Lin. National Cheng Kung University Hospital, Tainan, Taiwan

Purposes: To determine the efficacy of 3-day intravenous omeprazole plus antibiotics for $H$. pylori eradication in bleeding duodenal ulcer (DU). Methods: From Jul. 1995 to Mar. 1996, 50 patients with H. pylori-positive bleeding DU were allocated into 2 groups: $\mathrm{Gr} 1(\mathrm{n}=25)$ cases received a 3-day course of intravenous omeprazole $(80 \mathrm{mg}$ loading then $40 \mathrm{mg} \mathrm{q} 9 \mathrm{am}$ $\& 9 \mathrm{pm}$ ) plus ampicillin ( $1.5 \mathrm{gm}$ iv loading then $750 \mathrm{mg} \mathrm{q} 9 \mathrm{am}, 3 \mathrm{pm}, \&$ $9 \mathrm{pm})$; Gr $2(\mathrm{n}=25)$ followed protocol as $\mathrm{Gr} 1$ except the antibiotics to be metronidazole and erythromycin (both $500 \mathrm{mg}$ iv q $9 \mathrm{am}, 3 \mathrm{pm}, \& 9 \mathrm{pm}$ ). In each case, gastric biopsies over antrum, body, and cardia were done for histologic density of $H$. pylori (score $0-5$ ), before (to assess pre-treatment bacterial loads), 1 day after therapy (to test the clearance) and 2 months later (to test the eradication). The total $H$. pylori density (THPD) is a sum of scores from 3 biopsies (range 0-15). The $24 \mathrm{hr}$ intragastric $\mathrm{pH}$ meter (MIC Inc, Gastrograph Spark III, Swiss) was inserted on the 2nd day of therapy. Results: The clearance rates of group $1 \& 2$ were $92 \%(23 / 25)$ \& $88 \%(22 / 25)$, and the eradication rates were $64 \%(16 / 25) \& 80 \%(20 / 25)$. The percentage of intragastric $\mathrm{pH}>5.3$ during $24 \mathrm{hr}$ was not different between $H$. pylori non-eradicated and eradicated cases $(59.5 \pm 15.9 \% \mathrm{vs}$. $63.8 \pm 15.2 \%, \mathrm{p}>0.05$ ). The $H$. pylori eradicated cases had lower THPD than non-eradicated ones $(5.6$ vs 8.1, $\mathrm{p}<0.05)$. Conclusion: This 3-day intravenous course of anti- $H$. pylori therapy achieves quick clearance of bacteria. The individual response to omeprazole in such dosage disclosed insignificant variations in intragastric $\mathrm{pH}$ elevation to alter the success of eradication. To improve eradication rate, prolonged course or add-up of subsequent oral route would be rational and especially indicated for patients with higher bacterial loads.

\section{A:06 TWO-DAY VERSUS ONE-WEEK ANTI-HELICOBACTER THERAPY IN CONTROLLED BLEEDING ULCERS: A PROSPECTIVE RANDOMISED TRIAL}

N.S. Kung, J.J.Y. Sung ${ }^{1}$, P.W. Ng, W.F. Yuen, E. Chung, B.H. Lim, S.P.Y. Kwok, H.C. Ma. United Christian Hospital, Hong Kong; ${ }^{1}$ Prince of Wales Hospital, The Chinese University of Hong Kong, Hong Kong

One-week bismuth triple therapy is highly effective in curing $H$. pylori infection. Recently, a two-day regimen using bismuth, amoxycillin and tinidazole has achieved a $90 \%$ eradication. For patients hospitalised for ulcer bleeding, an effective ultra-short regimen allows medications to be completed before discharge.

Aim: To compare 2-day versus One-week triple therapy in curing $H$. pylori infection and bleeding peptic ulcers.

Methods: 100 patients (pts) with endoscopically proven non-actively bleeding DU or GU and confirmed $H$. pylori infection were randomised to receive EITHER bismuth subcitrate $120 \mathrm{mg}$, tetracycline $500 \mathrm{mg}$ and metronidazole $400 \mathrm{mg}$ four times daily for 1 week (BTM-7) OR bismuth subcitrate $240 \mathrm{mg}$, tetracycline $500 \mathrm{mg}$ and metronidazole $400 \mathrm{mg}$ four times daily for 2 days (BTM-2). Both pts groups also received omeprazole $20 \mathrm{mg}$ twice daily for the first week. Endoscopy was repeated 5 weeks after randomisation to determine ulcer healing and $H$. pylori status by rapid urease test, culture and histology.

Results: 92 pts had DU, 5 had GU and 3 had DU plus GU. The ulcers showed a visible vessel and/or adherent clot in 15 pts. Baseline characteristics and drop-out rates were similar in both groups. Ulcer healing at 5 weeks was 44/46 (95.7\%) in BTM-2 and 49/50 (98\%) in BTM-7 (intention to treat, $\mathrm{p}=0.61)$. $\mathrm{H}$. pylori eradication was achieved in $35 / 46(76.1 \%)$ in BTM-2 and 50/50 (100\%) in BTM-7 (intention to treat, $p=0.00024)$. No patient had ulcer rebleeding in either group.

Conclusion: Despite similar efficacy in ulcer healing, the 2-day antihelicobacter regimen is less effective than the one-week triple therapy in curing $H$. pylori infection.

\section{A:07 COMPARISON OF TWO DOUBLE THERAPIES (RANITIDIN PLUS AMOXYCILLINE VIS OMEPRAZOLE PLUS AMOXYCILLINE) IN PATIENTS WITH HELICOBACTER PYLORI POSITIVE DUODENAL ULCER}

N. Popovic, M. Glisic, P. Popovic, T. Milosavljevic, K. Todorovic, O. Matejic. Clinic for Gastroenterology and Hepatology, Clinical Center, Belgrade, Yugoslavia

The eradication of Helicobacter pylori / $/ \mathrm{SP} /$ may be presently achieved with many therapy schedule. Peptic suppression is one of the factors responsible for the in vivo efficacy of combined therapy for eradication of HP. There are, however, controversies regarding the influence of the acid lowering drug on HP eradication rates. Omeprazole /OME/ has been generally the antisecretory drug preferred in most of the clinical trial performed. The purpose of the present study was to determine if protonpumpinhibitors are more potent in HP eradication therapy as compared to H2-receptor antagonist Ranitidin $300 \mathrm{mg}$ with one antibiotic? 80 patients with the endoscopical diagnosis of duodenal ulcer /DU/ and positive HP status, were randomized into two treatment groups. I RAN $300 \mathrm{mg} / \mathrm{u}$.i.d. for 15 days + Amoxycilline $/ \mathrm{AMO} / 1 \mathrm{gr} / \mathrm{b}$.i.d. for 10 days and after RAN 300 $\mathrm{mg} /$ u.i.d for 15 days. II OME $20 \mathrm{mg} /$ b.i.d. for 10 days plus AMO $1 \mathrm{gr} / \mathrm{b}$.i.d. for 10 days and after OME $20 \mathrm{mg} / \mathrm{u}$.i.d for 20 days. All patients were endoscopied at the end of treatment. HP status was assessed by ureasa CLO-test and antral/body histology. Results: One patient had diarrhoa side effect. Healing of DU was observed in $34 / 40$ (85\%) patients of the group I and in $37 / 40$ (92\%) patients in group II. Eradication of the HP occurred in $27(67.5 \%)$ patients of the group I and $29(72.5 \%)$ patients of the group II. There was no significant difference between these two groups. Conclusion: The results show that under controlled condition there is not difference between RAN + AMO v/s OME + AMO in eradication of HP and in ulcer healing rate.

\section{A:08 OMEPRAZOLE vS TWO DIFFERENT DOSES OF LANSOPRAZOLE IN TRIPLE THERAPY ON H. PYLORI POSITIVE DUODENAL ULCER}

F. Catalano, U. Privitera ', G. Branciforte, R. Catanzaro, C. Bentivegna, A. Brogna, A. Blasi. University of Catania, Catania, Italy; ${ }^{1}$ Endoscopy Unit of Cannizzaro Hospital, Catania, Italy

Purpose of this paper was to describe the effect of Omeprazole (OME) $40 \mathrm{mg}$ vs Lansoprazole (LAN) at two different doses (30 and $60 \mathrm{mg}$ ) in H. pylori positive duodenal ulcer (DU). We enrolled $200 \mathrm{H}$. pylori +ve DU pts and randomized in 3 groups: 70 pts $(40 \mathrm{M}-30 \mathrm{~F}$, mean age 47.11 yrs, range 18-74) treated with OME $40 \mathrm{mg}$ for 20 days plus Amoxicillin (AMO) $2 \mathrm{~g}$ and Clarithromicin (CLA) $1 \mathrm{~g}$ for 10 days (Group A); $64 \mathrm{pts}$ (36 M-28 F, mean age $47.04 \mathrm{yrs}$, range 23-72) treated with LAN $30 \mathrm{mg}$ for 20 days plus AMO and CLA at same dose of Group A (Group B); 66 pts (30 M-36 F, mean age 45.95 yrs, range 21-75) treated with LAN $60 \mathrm{mg}$ plus AMO and CLA at same dose of Group A and B (Group C). Patients were reassessed by endoscopy, histology, CP-test at 6 weeks after the end of therapy. Data were analyzed using chi-square test and a $p<0.05$ was considered significant. Eight pts in Group A, 4 pts in Group B and 8 pts in Group in Group C dropped out. Our results show that $60 / 62$ pts $(96.8 \%)$ in Group A, 54/60 pts (90\%) in Group B and 56/58 pts (96.5\%) in Group C healed: no significant difference was found statistically. $\mathrm{H}$. pylori was eradicated in 58/62 pts (93.6\%) in Group A, $42 / 62$ pts (70\%) in Group B and $52 / 58$ pts $(89.7 \%)$ in Group C. Statistical analysis shows a $p=0.002$ (OME 40 vs LAN 30 ); a $p=0.015$ (LAN 60 vs LAN 30); and no significant difference between OME 40 and LAN 60. The histological grade of all treated pts showed improvement. In conclusion we evidence that OME 40 and LAN 60 plus AMO and CLA are effective in $\mathrm{H}$. pylori eradication. All used treatment are effective in healing DU.

\section{A:09 WHAT'S THE CLINICALLY FAVORED TRIPLE THERAPY?}

A.S. Ho ${ }^{1}$, S.C. Lee ${ }^{2}$, C.T. Hsu ${ }^{1} .{ }^{1}$ Tri-Service General Hospital, Taipei, Taiwan, R.O.C.; ${ }^{2}$ Institute of Nuclear Energy Research, A.E.C., Taipei, Taiwan, R.O.C.

Purpose: To find the fewer dosage, lesser side effect and shorter duration with high eradication regimen among the recent triple therapies.

Methods: Endoscopically proved 90 duodenal ulcer patients were randomly assigned with one of three regimens (Group A: DeNol $120 \mathrm{mg}$ qid + amoxicillin $500 \mathrm{mg}$ qid + metronidazole $250 \mathrm{mg}$ qid for 14 days, $\mathrm{n}$ = 30; Group B: lansoprazole $30 \mathrm{mg}$ bid + clarithromycin $500 \mathrm{mg}$ bid + amoxicillin $500 \mathrm{mg}$ qid for 14 days, $\mathrm{n}=30$; Group C: omeprazole $20 \mathrm{mg}$ bid + clarithromycin $250 \mathrm{mg}$ bid + metronidazole $500 \mathrm{mg}$ bid for 7 days, $\mathrm{n}$ $=30$ ). The $H$. pylori infection status was proved by CLO test and ${ }^{13} \mathrm{C}$-urea breath test (UBT) with the excess $\delta{ }^{13} \mathrm{CO}_{2}$ excretion of 5 per mil as upper limit. Eradication of $H$. pylori was assessed by two consecutive ${ }^{13} \mathrm{C}$-UBT at 4 and 8 weeks after the finishing treatment respectively. Results:

\begin{tabular}{lllllcl}
\hline Group & No. & Duration & Success & E.R. ${ }^{+}$ & Cost (US\$) & S.E.S.* \\
\hline A & 30 & 14 days & 23 & $76.7 \%$ & 70.5 & 4 \\
B & 30 & 14 days & 23 & $76.7 \%$ & 175.5 & 5 \\
C & 30 & 7 days & 27 & $90 \%$ & 70.3 & 2 \\
\hline
\end{tabular}

*S.E.S (Side effect score): Present 1; Absent 0, ${ }^{+}$E.R. (Eradication rate) $x^{2}=2.323$, $\mathrm{df}=2, \mathrm{p}=0.313$

Conclusions: Although there was no significant difference on eradication effect among each therapeutic group, group $\mathrm{C}$ was the fewer dosings and 
side effect regimen with the shorter duration and saving cost. The newer triple therapy with omeprazole $20 \mathrm{mg}$ bid + clarithromycin $250 \mathrm{mg}$ bid + metronidazole $500 \mathrm{mg}$ bid of 7 days duration is a good choice for $H$. pylori eradication.

\section{A:10 EFFICACY OF ONE-WEEK TRIPLE THERAPY WITH CLARITHROMYCIN, FURAZOLIDONE PLUS LANSOPRAZOLE OR COOLOIDAL BISMUTH SUBCITRATE FOR ERADICATION OF HELICOBACTER PYLORI}

W.Z. Liu, S.D. Xiao, W.W. Xu, Y. Shi. Shanghai Institute of Digestive Diseases, Shanghai, P.R. China

The Optimal drug regimen for eradication of Helicobacter pylori $(\mathrm{Hp})$ remains uncertain.

Aim: 1) To evaluate the efficacy of two drug regimens in eradication of $\mathrm{Hp}$ and healing of duodenal ulcer (DU).

Patients and Methods: 60 patients with DU or non-ulcer dyspepsia and $\mathrm{Hp}$ infection were randomly received one-week triple therapy with Clarithromycin (Cla) $500 \mathrm{mg} / \mathrm{d}$, Furazolidone $200 \mathrm{mg} / \mathrm{d}$ plus Lansoprazole $30 \mathrm{mg} / \mathrm{d}$ (group A) or CBS $480 \mathrm{mg} / \mathrm{d}$ (group B). Before and four weeks after end of therapy, patients were investigated with endoscopy and biopsy (4 from antrum and 2 corpus) for Hp culture and histology.

Results: 57 patients completed the study. The rates of Hp eradication in group A and B were $92.6 \%$ (25/27) and 90\% (27/30) respectively (P< 0.05 ). The primary resistant rate of Hp strains to Cla was 7.5\% (4/53), and no patient infected with resistant $\mathrm{Hp}$ strain to $\mathrm{Cla}$ succeeded in eradication. The healing rates of DU were $94.4 \%(17 / 18)$, in group A and $100 \%(18 / 18)$ in group $B(P>0.05)$. Only two patients complained of mild nausea.

Conclusions: (1) Both of the regimens are highly effective in the eradication of $\mathrm{Hp}$ and the healing of DU, and are well tolerated. (2) The primary resistance of $\mathrm{Hp}$ strains to Cla is the main cause of the treatment failure.

\section{A:11 TRIPLE THERAPY (OMEPRAZOL + AMOXICILLIN + CLARITHROMYCIN) FOR HELICOBACTER PYLORI ERADICATION IN PATIENTS WITH CHRONIC GASTRITIS. TWELVE DAYS BETTER THAN SIX}

C. Hermida, J.A. Moreno, P. Carpintero, J.M. Mateos, R. GaGrávalos, J.M. Pajares. Servicio de Medicina Digestiva, Hospital Universitario de La Princesa, Universidad Autónoma de Madrid, Spain

Intro: Modern therapies for eradication of Helicobacter pylori try to be more effective and to achieve better compliance being shorter and cheaper. Some seven-days regimens with omeprazole, amoxicillin and clarithromycin have proved high eradication rates. In Spain available packaging of both antibiotics used carries 12 capsules in. If we use 7 days regimens we need double number of packages and lots of pills are wasted.

Aim: To ascertain the efficacy of a triple therapy with omeprazole, amoxicillin and clarithromycin for Helicobacter pylori eradication in regimens of 6 and 12 days.

Patients and Methods: We conducted a clinical trial to eradicate Helicobacter pylori infection in patients with chronic gastritis. 105 consecutive patients (58 M/47 F, mean age: 47,53 , range: $15-83$ ) submitted to upper digestive tract endoscopy because symptoms of dyspepsia, were included in the study. Diagnosis of Helicobacter pylori infection was achieved when, at least, two of the following tests were positive: histologic examination of antral biopsy specimens in frozen tissue sections on $\mathrm{H}-\mathrm{E}$ and Giemsa, rapid urease test (Jatrox-test) and $\mathrm{C}^{13}$ urea breath test. Triple therapy consisting in omeprazole $20 \mathrm{mg} / \mathrm{bid}$, amoxicillin $1 \mathrm{~g} / \mathrm{bid}$ and clarithromycin 500 $\mathrm{mg} / \mathrm{bid}$ was given to patients at the time of diagnosis. Duration of treatment was non-randomly assigned for 6 and 12 days. Control of eradication was assessed by $C^{13}$ urea breath test after 6 weeks of finishing treatment. Statistical analysis was performed using $\chi^{2}$ test with Yates correction.

Results: Eradication rates in the different groups are:

$\begin{aligned} 6 \text { Days } & 61.1 \%(33 / 54) \\ 12 \text { Days } & 84.3 \%(43 / 51)\end{aligned}$

Statistical difference of eradication $(p<0.008)$ was found between both regimens (6 vs 12 days). Costs of the 2 regimens were 85 and 170 \$, respectively for 6 and 12 days.

Conclusion: In patients with chronic gastritis a 12 days triple therapy (Omeprazol + Amoxicillin + Clarithromycin) eradicates Helicobacter pylori better than a shorter 6 days regimen.
4A:12 SHORT-TERM LOW-DOSE TRIPLE THERAPY FOR THE ERADICATION OF HELICOBACTER PYLORI: A RANDOMIZED, DOUBLE BLIND, CONTROLLED STUDY

F. Bazzoli, R.M. Zagari, S. Fossi, P. Pozzato, G. Alampi, S. Sottili, P. Simoni, C. Mwangemi, L. Ricciardiello, A. Roda, E. Roda. Cattedra di Gastroenterologia, Università di Bologna, Italy

Background: a simple safe and effective short term (1 week) low dose triple therapy, Omeprazole $20 \mathrm{mg}$ u.i.d. + Clarithromycin $250 \mathrm{mg}$ b.i.d. + Tinidazole $500 \mathrm{mg}$ b.i.d. (OCT), has been developed for the eradication of Helicobacter (H.) pylori (Eur J Gastroenterol 1994; 6: 773-7) in response to the problems seen with standard triple and dual therapies. Consistent results have been reproduced by several investigators in different countries with the same regime, whilst increasing dosages and duration of treatment does not seem to improve success rate. Aim: This is a double blind, randomized controlled trial to evaluate the efficacy and safety of OCT in comparison to even simpler combinations of the three considered agents. Methods: 128 patients (68 males, 60 females, age (yrs) range 22-76, mean 53) with non ulcer dyspepsia and $\mathrm{H}$. pylori infection were randomly allocated in four treatment groups receiving for 1 week: clarithromycin $250 \mathrm{mg}$ b.i.d (group $\mathrm{C}, \mathrm{n}=32$ ) or omeprazole $20 \mathrm{mg}$ u.i.d, clarithromycin $250 \mathrm{mg}$ b.i.d. (group OC, $\mathrm{n}=32$ ) or clarithromycin $250 \mathrm{mg}$ b.i.d, tinidazole $500 \mathrm{mg}$ b.i.d (group CT, $\mathrm{n}=32$ ) or omeprazole $20 \mathrm{mg}$ u.i.d, clarithromycin $250 \mathrm{mg}$ b.i.d., tinidazole $500 \mathrm{mg}$ b.i.d (group OCT, $\mathrm{n}=32$ ). $\mathrm{H}$. pylori infection as well as eradication was assessed by histology (Haematoxylin/Eosin, Giemsa), culture, quick urease test and ${ }^{13} \mathrm{C}$-Urea Breath Test $\left({ }^{13} \mathrm{C}\right.$-UBT) before and 4 weeks after the end of treatment. Drug tolerability was evaluated by patient interview and compliance by pill counting at the end of treatment. Results: The four groups of patients had similar demographic and clinical characteristics. All patients completed the treatment and took more than $90 \%$ of the prescribed medication. Only one patient discontinued treatment due to side effects.

\begin{tabular}{llc}
\hline Treatment & Eradication rate & $95 \% \mathrm{CI}$ \\
\hline $\mathrm{C}$ & $6.3 \%(2 / 32)$ & $0-14.6$ \\
OC & $31.3 \%(10 / 32)$ & $15.2-47.3$ \\
CT & $59.4 \%(19 / 32)$ & $42.4-76.4$ \\
OCT & $93.8 \%(30 / 32)$ & $85.4-100$ \\
\hline
\end{tabular}

Differences in eradication rate in the four groups were statistically significant (at least $\mathrm{p}<0.025$ ). Conclusions: this randomized, double blind, controlled study confirms that the combination of omeprazole, clarithromycin and tinidazole at low dosages and just for one week is highly effective for $\mathrm{H}$. pylori eradication. Simpler combinations of the same agents are far less effective. The high success rate is probably linked to lack of side effects, patient compliance and synergy of all three agents.

\section{A:13 LANSOPRAZOLE (30 mg OD vs BID) WITH AMOXICILLIN AND CLARITHROMYCIN TO CURE HELICOBACTER PYLORI INFECTION}

A. Burette ', V. Lamy ${ }^{2}$, B. Ramdani ${ }^{1,2}$, J. Cappelli ${ }^{2}$, C. De Prez ${ }^{1}$, Y. Glupczynski ${ }^{3} \cdot{ }^{1}$ Nv. Clin. Basilique, Brussels, Belgium; ${ }^{2}$ Hôpital Civil de Jumet, Belgium; ${ }^{3}$ Hôpital A. Vésale, Charleroi, Belgium

In this double-blind, multicenter study, 99 patients with Helicobacter pylori (Hp) associated NUD, DU or GU were randomly assigned to one of the following triple therapies administered for 10 days: Group 1: lansoprazole (LA) $30 \mathrm{mg}$ od (before meals) + amoxicillin (AM) $1 \mathrm{~g}$ bid (after meals) + clarithromycin (CL) $500 \mathrm{mg}$ tid (after meals); Group 2: LA $30 \mathrm{mg}$ bid + AM $1 \mathrm{~g}$ bid + CL $500 \mathrm{mg}$ tid. The $H p$ status was assessed before treatment and 4- 6 weeks post-treatment in antral and corporeal biopsies by urease test, culture and histology. Eradication was defined as the absence of $\mathrm{Hp}$ in all post-treatment samples. 13C-urea breath test was performed 3 months post-treatment to confirm $H p$ eradication. Susceptibility testing of pre- and post-treatment isolates to $\mathrm{CL}$ was performed by disc diffusion method. Patients were considered as compliant if they took $\geq 80 \%$ of the treatment. Results: 7/99 patients were lost to follow-up. Among the $84 / 92$ patients who completed the study ( $48 \mathrm{M}$, mean age: 48 years, 24 DU, $8 \mathrm{GU}), 76$ were considered compliant to the treatment. Cure of $H p$ infection was respectively achieved in $71 / 76(93 \%, 95 \% \mathrm{CI}: 88-99)$ and $77 / 84$ (92\%, 95\% CI 86-98) of the patients according to the Per Protocol and the Intention To Treat analyses. Pre-treatment resistance to CL was found in 8/81 (10\%) of the $H p$ strains. Cure of $H p$ infection was achieved in $4 / 7$ of these cases. Mild adverse events, including dysgeusia (18\%) and diarrhea $(16 \%)$, occurred in about $50 \%$ of the patients but treatment was discontinued in only 2 of them. Conclusion: Triple therapies with LA, AM and $\mathrm{CL}$ for 10 days are very effective regimens to cure $H p$ infection. The overall high cure rate observed in this study suggests that both regimens (LA $30 \mathrm{mg}$ od or bid) are very successful. Treatment failure occurs in about $50 \%$ of the cases when the infecting Hp strain is CL-resistant. 


\section{A:14 OVER 95\% OF PATIENTS REMAIN H. PYLORI NEGATIVE 6 MONTHS AFTER ONE WEEK LOW-DOSE ERADICATION THERAPY}

J.J. Misiewicz ${ }^{1}$, A.W. Harris ${ }^{1}$, K.D. Bardhan ${ }^{2}$, S. Levi ${ }^{3}$, H. Langworthy ${ }^{4} .{ }^{1}$ Central Middlesex Hospital, London; ${ }^{2}$ Rotherham General Hospital; ${ }^{3}$ Wexham Park Hospital, Slough; ${ }^{4}$ Lederie, UK

Introduction: We have previously shown that $H$. pylori (Hp) can be eradicated in the majority of patients with a 7 day low dose triple therapy containing a proton pump inhibitor (PPI) in combination with 2 antibiotics. It is unclear whether patients remain free of infection 6 months after treatment with these regimens. This study investigated the Hp reinfection or recrudescence 6 months after 4 different one week regimens.

Methods: A multicentre, prospectively randomized, parallel group, single blind study was conducted in $\mathrm{Hp}$ positive (positive $\mathrm{CLO}^{\oplus}$ and positive ${ }^{13} \mathrm{C}$ urea breath test (UBT)) patients with endoscopic DU and/or nonulcer gastritis. Treatment was either lansoprazole (L) $30 \mathrm{mg}$ plus 2 of clarithromycin (C) $250 \mathrm{mg}$, amoxycillin (A) $1 \mathrm{~g}$, metronidazole (M) 400 $\mathrm{mg}$ or omeprazole (O) $20 \mathrm{mg}$ plus A $1 \mathrm{~g}$ and $\mathrm{M} 400 \mathrm{mg}$; all give twice daily for one week. Endoscopy and UBT were performed $\geq 6$ months after treatment in those patients in whom UBT had been negative $\geq 28$ days after treatment. Ethics approval and written informed consent was obtained.

Results: 304 patients returned for UBT $>6$ months after treatment. The proportion of patients remaining Hp negative is shown below:

\begin{tabular}{llll}
\hline $\operatorname{LAC} n(\%)$ & LAM n (\%) & LCM n (\%) & OAM n (\%) \\
\hline $80 / 83(96.4 \%)$ & $68 / 70(97.1 \%)$ & $77 / 78(98 \%)$ & $72 / 73(98.6 \%)$ \\
\hline
\end{tabular}

There were no significant differences $(\mathrm{p}>0.05)$ between treatments.

Conclusion: 6 months after treatment with LAC, LCM, LAM or OAM $>96 \%$ of patients remain $\mathrm{Hp}$ negative.

This research was funded by Lederle Laboratories, UK.

\section{A:15 ONE WEEK LOW-DOSE H. PYLORI ERADICATION THERAPY HEALS $90 \%$ OF DUODENAL ULCERS}

J.J. Misiewicz ${ }^{1}$, A.W. Harris ${ }^{1}$, K.D. Bardhan ${ }^{2}$, S. Levi ${ }^{3}$, H. Langworthy ${ }^{4} .1$ Central Middlesex Hospital, London, UK; ${ }^{2}$ Rotherham General Hospital, UK; ${ }^{3}$ Wexham Park Hospital, Slough, UK; ${ }^{4}$ Lederle. UK

Introduction H. pylori $(\mathrm{Hp})$ can now be eradicated in the majority of patients with 7 days of treatment with a proton pump inhibitor (PPI) in combination with 2 antibiotics. It is unclear if PPI treatment should be continued beyond 7 days in patients with duodenal ulcer (DU). This study investigated the efficacies of 4 one week Hp eradication regimens in the healing of DU. Methods A multicentre, prospectively randomised, parallel group, single blind study was conducted in the UK and Eire in Hp positive (defined as a positive $\mathrm{CLO}^{\circledR}$ and positive ${ }^{13} \mathrm{C}$ urea breath test (UBT)) patients with endoscopic DU. Treatment was either lansoprazole (L) $30 \mathrm{mg}$ plus two of clarithromycin (C) $250 \mathrm{mg}$, amoxycillin (A) $1 \mathrm{~g}$, metronidazole (M) $400 \mathrm{mg}$ or omeprazole (O) $20 \mathrm{mg}$ plus A $1 \mathrm{~g}$ and M $400 \mathrm{mg}$; all given twice daily for one week. Endoscopy and UBT were performed $\geq 28$ days following the end of treatment. Ethics approval was given and written informed consent obtained. Results 262 patients fulfilled the entry criteria, of whom 237 returned for follow-up endoscopy. The proportion of patients in whom DU was healed, is shown below with Hp eradication status: -

\begin{tabular}{llll}
\hline LAC n (\%) & LAM n (\%) & LCM n (\%) & OAM n (\%) \\
\hline $53 / 60(88.3 \%)$ & $52 / 56(92.9 \%)$ & $49 / 55(89.1 \%)$ & $60 / 66(90.9 \%)$ \\
$3 / 7$ unhealed & $4 / 4$ unhealed & $2 / 6$ unhealed & $3 / 6$ unhealed \\
Hp+ve & Hp+ve & Hp+ve & Hp+ve \\
\hline
\end{tabular}

There were no significant differences $(p>0.05)$ in DU healing between treatments. Conclusion Treatment with LAC, LCM, LAM or OAM for one week heals DU in about $90 \%$ of patients. This research was funded by Lederle Laboratories, UK.

\section{A:16 ONE-HOUR TOPICAL METHOD vS OMEPRAZOLE PLUS AMOXYCILLIN IN ERADICATION OF H. PYLORI IN DUODENAL ULCER PATENTS}

K. Przytulski, J. Reguła, A. Marek ${ }^{1}$, J. Ostrowski, A. Nowak ' , E. Butruk. Medical Centre for Postgraduate Education, Institute of Oncology, Warsaw, Poland; ${ }^{1}$ Silesian Medical Academy, Katowice, Poland

One-hour topical method (described in Am J Gastr 1995, 90, 63) was effective in eradication of $\mathrm{H}$. pylori in $97 \%$ of gastritis patients. Omeprazole plus amoxycillin eradication rate in duodenal ulcer patients varies from 0 to $82 \%$. The aim of this trial was to compare the two methods in a randomised, prospective study.

Eighty patients ( 21 female, 59 male; median age: 43 , range 18-73) with duodenal ulcer were randomised into one of the following groups. Group 1: 40 patients were given ranitidine $150 \mathrm{mg}$ bid for 6 weeks and then omeprazole $20 \mathrm{mg}$ b.i.d. plus pronase 30.000 units b.i.d. for 2 days. On the next day a solution ( $100 \mathrm{ml}$ of $7 \%$ natrium bicarbonate containing $4000 \mathrm{mg}$ of amoxycillin, $2000 \mathrm{mg}$ of bismuth subnitrate, $1000 \mathrm{mg}$ of metronidazole and 30.000 units of pronase) was instilled into the stomach for 1 hour using an intestinal tube with the balloon occluding duodenum. Group 2: 40 patients treated with omeprazole 20 b.i.d. and amoxycillin $1000 \mathrm{mg}$ b.i.d. for 2 weeks, followed by ranitidin $150 \mathrm{mg}$ b.i.d. for next 4 weeks. Eradication was regarded as successful when urease test, histology and urea breath test were negative.

Eradication rates in groups 1 and 2 were $2.5 \%$ and $35 \%$ in "intention-totreat" analysis, respectively. Minor side-effects (nausea, vomiting, diarrhea) were encountered in $40.5 \%$ and $15.3 \%$ of patients, respectively. Topical method was poorly tolerated in $54 \%$ of patients.

One-hour topical method as well as omeprazole/amoxicilline treatment are ineffective in eradication of $\mathrm{H}$. pylori in duodenal ulcer patients.

\section{A:17 COMPARISON OF THE EFFICACY OF TWO, SHORT-TERM, TRIPLE THERAPIES BASED ON CLARITHROMYCIN, IN THE ERADICATION OF HELICOBACTER PYLORI (HP): A} RANDOMIZED STUDY

S. Georgopoulos ${ }^{1}$, A. Mentis ${ }^{2}$, S. Karatapanis ${ }^{1}$,

A.S. MylonakisKatranis ${ }^{2}$, V. Artikis ${ }^{2}{ }^{1}$ GI Dept., ${ }^{2}$ Dept. of Internal Medicine of Athens "ELPIS" Hospital, ${ }^{3}$ Dept of Bacteriology, Hellenic Pasteur Institute, Athens, Greece

Recent studies have shown that newer, one week, triple therapies based on Clarithromycin (CL) are highly effective and safe in treating Hp infection.

The aim of our study was to compare the $\mathrm{Hp}$ eradication rates achieved by two, one week, triple regimens that involve either one or two antibiotic agents.

Patients - Methods: Seventy-eight patients (aged 19-83 yrs, mean 45.6) with a documented Hp infection (by CLO-test, histology and culture) were randomized in two treatment groups: Group A ( $n=40,27 \sigma, 62.5 \%$ smokers) received Omeprazole (Ome) $20 \mathrm{mg}$ bid + CL $500 \mathrm{mg}$ bid + Metronidazole (Met) $500 \mathrm{mg}$ bid, for one week. Group B $(\mathrm{n}=38,24 \sigma$, $61.3 \%$ smokers) received Ome $20 \mathrm{mg}$ bid + CL $500 \mathrm{mg}$ bid + TBD (De Nol) $120 \mathrm{mg}$ gid, for one week. All patients underwent a new endoscopy 4 weeks after the end of treatment to assess eradication of $\mathrm{Hp}$. Antibiotic sensitivity test was performed whenever $\mathrm{Hp}$ isolates were successfully cultured.

Results: Eradication of $\mathrm{Hp}$ was achieved in $34 / 40$ (85\%) patients of group A vs $34 / 38(89.5 \%)$ of group B ( $p=N S)$. Culture and antibiotic sensitivity test revealed 12/32 (37.5\%) Met resistant $\left(\mathrm{Met}^{\mathrm{R}}\right) \mathrm{Hp}$ strains in group A and $13 / 31(41.9 \%)$ in group B ( $p=N S)$. In contrast, only one patient (1.63\%) had an Hp strain with primary resistance to CL and notably didn't respond to both therapies. The regimens were comparable according to their efficacy on Met sensitive $\left(\mathrm{Met}^{\mathrm{S}}\right)$ strains [20/20 (100\%) vs 17/19 $(89.5 \%), p=N S]$. In contrast, the response to treatment of patients with $\mathrm{Met}^{R}$ strains was significantly lower in group A compared to group $B$ [7/12 $(58.3 \%)$ vs $12 / 13$ (92.3\%), p < 0.05]. Five patients in group A experienced mild to moderate adverse events compared to one patient in group B.

Conclusion: The efficacy of the newer, short-term, triple regimen involving two antibiotics probably is depended on the incidence of $\mathrm{Met}^{R} \mathrm{Hp}$ strains. In area with low CL resistance of $\mathrm{Hp}$, an alternative mono-antibiotic triple regimen may be equally effective and well tolerated.

\section{A:18 DUODENAL ULCER HELICOBACTER PYLORI (HP) POSITIVE: THERAPY WITH RANITIDINE (R) + CLARITHROMICINE (C) + METRONIDAZOLE (M) VERSUS OMEPRAZOLE (O) + CLARITHROMICINE + METRONIDAZOLE}

N. Saccà, A. De Medici, S. Rodinò, M. De Siena, A. Giglio. Servizio di Endoscopia Digestiva, Ospedale Ciaccio, Catanzaro, Italia

To compare two different therapeutic regimens and to evaluate their effects on HP eradication we conducted a prospective study on 123 patients with duodenal ulcer and HP associated gastritis. The patients were randomly assigned to the following treatment groups: A) Ranitidine $150 \mathrm{mg}$ bi.d. for a month + C $250 \mathrm{mg}$ b.i.d. for a week + M $250 \mathrm{mg}$ t.i.d. for a week; B) Omeprazole $20 \mathrm{mg}$ for a month $+\mathrm{C}$ b.i.d. for a week $+\mathrm{M}$ t.i.d. for a week. 58 patients were assigned to the regimen $A$ and 65 patients to the regimen $B$. The patients underwent endoscopy at the beginning of the study and 2 months after the end of the therapy. HP status was determined with urease test and histology ( 2 biopsies each one taken from the antrum and corpus of the stomach. Eradication was achieved as follows: Group A 47/58 $=81 \%$, group B $52 / 65=80 \%$ Duodenal ulcer were completely healed in all patients. Both regimes were tolerated. No statistically significant differences ( $\mathrm{X} 2$ test) were found between the two groups. 
Conclusions: Ranitidine $150 \mathrm{mg}$ b.i.d. $+\mathrm{C}+\mathrm{M}$ is as effective for HP eradication as omeprazole $20 \mathrm{mg}+\mathrm{C}+\mathrm{M}$. The patients compliance to one week therapy is excellent.

\section{A:19 THE ROLE OF QUADRUPLE THERAPY IN THE TREATMENT OF HELICOBACTER PYLORI}

G. Daskalopoulos, Y.Y. Ho, D. Mehanna, K. Chen. Inner West Endoscopy Centre, Sydney, Australia

Introduction: The definitive treatment for $\mathrm{H}$. pylori has yet to be established. Triple therapies either with bismuth or a proton pump inhibitor currently appear to be the most often used treatments. There have, however, been several studies with quadruple therapy which seem to confirm more consistent higher eradication rates. There have been no comparative studies into which quadruple therapies may be more effective. Aim: To compare three different quadruple therapies in the eradication of $\mathrm{H}$. pylori. Methods: 161 patients with dyspeptic symptoms confirmed at endoscopy with biopsy as having H. pylori between June 94 and July 95 were entered into the study. Patients were randomised to one of three treatment groups. Each treatment was given for 2 weeks. (A) Colloidal bismuth 1 qid, tetracycline $250 \mathrm{mg}$ qid, metronidazole $200 \mathrm{mg}$ tid, lansoprazole $30 \mathrm{mg}$ bd, (BTML- 45 patients). (B) Colloidal bismuth 1 qid, tetracycline 250 $\mathrm{mg}$ qid, metronidazole $200 \mathrm{mg}$ tid, roxithromycin $150 \mathrm{mg}$ bd (BTMR - 36 patients.) (C) Colloidal bismuth 1 qid, tetracycline $250 \mathrm{mg}$ qid, roxithromycin $150 \mathrm{bd}$, lansoprazole $30 \mathrm{mg}$ bd (BTRL - 47 patients). 128 patients returned for follow up assessment 4 weeks after the completion of treatment. Assessment for $\mathrm{H}$. pylori before and after treatment was made with 5 antral biopsies, 1 urease, 1 phase microscopy, 1 histopath (giemsa) and 2 culture. Lansoprazole was used (group A and C) 2 extra biopsies from the fundus were taken after treatment for, 1 phase microscopy and 1 histopath. Statistical analysis was performed using Mann-Whitney rank sum test. Analysis of eradication was made both on a per protocol (P.P.) basis and an intention to treat (I.T.T) basis. Results: Eradication of H. pylori.

\begin{tabular}{lcr}
\hline (I.T.T.) & Per protocol (P.P.) & Intention to treat \\
\hline Total & $110 / 128(88.9 \%)$ & $110 / 161(68.3 \%)$ \\
BTML & $38 / 45(84.4 \%)$ & $38 / 56(67.9 \%)$ \\
BTRL & $39 / 47(83.3 \%)$ & $39 / 55(70.9 \%)$ \\
BTMR & $33 / 36(91.7 \%)$ & $33 / 50(66.0 \%)$ \\
\hline
\end{tabular}

There was no significant difference between treatment groups ( $p>$ 0.05). Conclusion: (1) Quadruple therapies achieve high eradication rates for H. pylori. (2) Although the combination BTMR achieved the highest eradication rate of $91.7 \%$ this was not significantly better than BTML or BTRL. BTMR has the added advantage in lower cost of the drugs.

\section{A:20 RANDOMISED STUDY COMPARING TWO SEVEN DAYS TRIPLE THERAPIES WITH LANSOPRAZOLE AND LOW DOSE OF CLARITHROMYCIN PLUS AMOXICILLIN OR TINIDAZOLE FOR H. PYLORI ERADICATION}

H. Lamouliatte, P. Talbi, R. Cayla, F. Zerbib, F. Megraud. Hôpital Saint-André, Bordeaux, France

For $H$. pylori (HP) eradication (HPE), two seven days triple therapies with PPI and two antibiotics have obtained eradication rate higher than 90\%: 1/PPI-Clarithromycin (Clari) $250 \mathrm{mg}$ bid and Tinidazole (Tini) or Metronidazole (Metro) 2/PPI-Clari $500 \mathrm{mg}$ bid and Amoxicillin (Amox). The aim of this study was to compare two seven days triple therapies using low dose of Clari.

Methods: HP infection was assessed on antral and fundic biopsies at the inclusion and 4 weeks after the end of the treatment by 4 methods: CLOtest at the inclusion, histology, culture and PCR. Clari resistance was defined by contact resistance with an agar diffusion method and Metro resistance by a $\mathrm{MIC}>8 \mathrm{mcg} / \mathrm{ml}$ (E-test). HP positive patients were randomly allocated to receive either: 1/Lansoprazole (Lanso) $30 \mathrm{mg}$ bid + Clari $250 \mathrm{mg}$ bid and Tini $500 \mathrm{mg}$ bid (LCT group) or 2/Amox $1 \mathrm{~g}$ bid (LCA group) during 1 week. Patients with duodenal ulcer (DU) took Lanso $30 \mathrm{mg}$ od until day 28. HPE was defined by negativity of all diagnostic methods at control.

Results: 65 patients (43 male, mean age 44.6 years old, 36 with DU, 29 with non ulcer dyspepsia) were included. In intention-to-treat analysis, the HPE rates were respectively $56.2 \%(18 / 32)$ in the LCA group and $69.6 \%$ in the LCT group (23/33) (NS). In per protocol analysis, the HPE rates were respectively $69.2 \%(18 / 26)$ in the LCA group and $79.3 \%(23 / 29)$ in the LCT group (NS). Before treatment, 31 out of $54(57.4 \%)$ isolated strains were resistant to Metro: $14 / 26(53.8 \%)$ in the LAC group and 17/28 $(60.7 \%)$ in the LCT group. 9 out of $54(16.6 \%)$ strains were resistant to Clari: $3 / 26(11.5 \%)$ in the LCT group and 6/28 (21.4\%) in the LCA group. Metro-resistant strains were eradicated in $64.2 \%(9 / 14)$ in the LCT group.
Among Clari-resistant strains, 33\% (3/9) were eradicated in both group. Side effects were present in only $6.6 \%(2 / 33)$ of patients treated with LCT (diarrhea) and 6.2\% (2/32) in LCT group (diarrhea and metallic taste).

Conclusion: 1/ the results of the association PPI-Amox and Clari 250 $\mathrm{mg}$ bid are disappointing and lower than those with Clari $500 \mathrm{mg}$ bid. $2 /$ HPE rate with the PPI-Clari-Tini combination is lower than $80 \%$ because of the high rate of Metro-resistant strains. 3/ Tolerance is good with very few side effects.

\section{A:21 ARE THERE ANY CLINICAL OR PHARMACOLOGICAL PREDICTORS IN DUAL THERAPY FOR HP-ERADICATION?}

G. Treiber, U. Klotz. Robert-Bosch-Hospital, Auerbachstr. 110, D-70376 Stuttgart, Germany

Dual therapy with an acid inhibitor and one antibiotic is a widely used treatment option for helicobacter pylori (HP) eradication, although triple therapy with 2 antibiotics is becoming the new "gold standard". Aims: Comparing the efficacy of different acid inhibitors in combination with amoxicillin (advantage: no resistance problems), evaluating clinical and/or pharmacological parameters predicting HP-eradication success. Methods: prospective, investigator blinded trial, treating HP-positive patients with gastric (GU), duodenal ulcers (DU) or erosive gastritis (EG) for 2 wk. Patients were assigned in random order to a combination of amoxicillin 1 $\mathrm{g}$ bid and lansoprazole $30 \mathrm{mg}$ bid (LA) or omeprazole $20 \mathrm{mg}$ bid (OA) or ranitidine $300 \mathrm{mg}$ bid (RA). On day 4-6 of therapy, we investigated under standardised conditions concomitantly gastric $\mathrm{pH}$ and pharmacokinetics for one dose interval $(12 \mathrm{~h})$. Before and $4 \mathrm{wk}$ after therapy HP status was checked by $13 \mathrm{C}$ urea breath test (UBT). Results: After evaluating 60 patients (20 per group), the trial was stopped because of comparable but insufficient eradication rates (HP-ER). In contrast to most studies our 3 groups were matched for age, sex, weight, smoking habits, initial diagnosis, liver/renal function and history of previous ulcers. In 54/60 patients, total HP-ER is $44.4 \%: 39 \%$ (LA), $42 \%$ (OA) and $53 \%$ (RA), n.s. LA and OA produced higher mean (4.6 vs 5 vs 3.8 ) and median (4.4 vs 5.3 vs 3.8$)$ pH values than RA and gave a longer acid suppression (time with $\mathrm{pH}>4: 68 \%$ vs $75 \%$ vs $47 \%$ ), all differences $p<0.01$. Surprisingly, this resulted in comparable HP-ER between these groups. In patients becoming HP- and remaining $\mathrm{HP}+$ no significant differences were found for mean and median $\mathrm{pH}$, time of acid suppression with a $\mathrm{pH}>4$, initial UBT values (indirectly reflecting bacteria density/gastritis), minimum and maximum serum levels for amoxicillin, time of maximum ( $\mathrm{t}$ max) and extent (AUC) of amoxicillin absorption. From all clinical parameters initial diagnosis (best HP-ER for GU, worst for EG), age and history of previous ulcers ( $p<0.05$ each) could predict treatment success. Compliance from plasma level monitoring was extremly good (93\%). Conclusions: Acid inhibition is important in dual therapy with amoxicillin, but apparently not its extent. Ranitidine adequately dosed is as effective for HP-eradication as proton-pump inhibitors. There are neither pharmacokinetic nor -dynamic differences in patients being HP+ or HP- after therapy. In a subgroup of ulcer patients over 50 years with a previous history of PU dual therapy has an HP-ER of around $80 \%$.

\section{A:22 HELICOBACTER PYLORI INFECTION: DOUBLE, TRIPLE OR QUADRUPLE THERAPY WITH OMEPRAZOLE OR RANITIDINE IN PATIENTS WITH ACTIVE DUODENAL ULCER}

Francesco Di Mario. G.I.S.U. (Interdisciplinary Group for Ulcer Study), Italy

Aim. To compare Hp eradication rates using two dosages of Ranitidine triple therapy with Omeprazole (OME) double, triple or quadruple therapy. Methods. 397 consecutive patients, referred to different Endoscopy Units in North-East of Italy, with active DU and Hp infection entered the study. Each patient was randomly assigned to one of the following treatment schedules: 1) OME $40 \mathrm{mg}$ plus AMO $4 \times 500 \mathrm{mg}$; 2) OME $40 \mathrm{mg}$ plus AMO $4 \times 500 \mathrm{mg}$ plus METRO a $\times 250 \mathrm{mg}$; 3) OME $40 \mathrm{mg}$ plus AMO $4 \times 500 \mathrm{mg}$ plus METRO a $\times 250 \mathrm{mg}$ plus BCS $4 \times 120 \mathrm{mg}$; 4) RAN $300 \mathrm{mg}$ plus AMO $4 \times 500 \mathrm{mg}$ plus METRO $4 \times 250 \mathrm{mg}$; 5) RAN $2 \times 300 \mathrm{mg}$ plus AMO $4 \times 500 \mathrm{mg}$ plus METRO $4 \times 250 \mathrm{mg}$. All antibiotics treatment lasted for two weeks while antisecretory treatment did four. Hp status was confirmed by histology on 6 biopsies ( 2 gastric antrum, 2 angulus and 2 body; Hematossilineosin and Giemsa modified stain) and with rapid urease test (CLO test). An endoscopy was performed at baseline and 1 and 4 months after the beginning of the treatment. Results. All patients completed the therapy. After 1 month 23 patients were unhealed (13 Hp-cleared and $10 \mathrm{Hp}$-positive) and left the study. After 4 months 17 patients presented DU recurrence (2 Hp-negative and $15 \mathrm{Hp}$-positive). 380 patients persisted healed (290 Hp-negative and $90 \mathrm{Hp}$-positive). The percentage of $\mathrm{Hp}$ eradication for each regimen were as follows: 1) 56.6; 2) 78.4 ; 3) 81.4 ; 4) 76.8; 5) 74.6. Conclusions. 1) Omeprazole triple and 
quadruple therapies have comparable eradication rates about $80 \%$. 2) Triple therapy with Ranitidine $300 \mathrm{mg}$ cured almost $80 \%$ of Hp-infected pts; 600 mg did not enhance eradication rate. 3) Double therapy OME plus AMO cannot be proposed for Hp-eradication, having proved an eradication rate of about $60 \%$.

\section{A:23 ERADICATION OF H. PYLORI INFECTION WITH FIVE DIFFERENT DRUG REGIMES}

M. Katičić, V. Presečki, M. Marušić, M. Prskalo, M. Tiĉak, B. Šabarić, V. Čolić-Cvrlje, M. Dominis, S. Kalenić, S. Džebro, B. Papa. Clinical Hospital "MERKUR", Medical School, University of Zagreb, Croatia

The aim of our study was to compare the efficacy and tolerability of five different therapeutic regimes for $\mathrm{H}$. pylori eradication.

Methods: 468 consecutive patients (M/F 395/233, mean age 51), undergoing endoscopy, were screened for H. pylori. $402(86 \%)$ patients, with confirmed $\mathrm{H}$. pylori infection by rapid urease test (CLO), histology (2-corpus, 2-antrum), serology (IgG) and microbiology were allocated to one of five regimens: A) Omeprazole $20 \mathrm{mg}$ b.d., Amoxicillin $1 \mathrm{~g}$ b.d. for 14 days $(\mathrm{n}=130)$, B) Omeprazole $20 \mathrm{mg}$ b.d., Amoxicillin $1 \mathrm{~g}$ b.d. for 14 days, metronidazole 500 b.d. for 10 days $(n=146), C)$ Omeprazole $20 \mathrm{mg}$ b.d., Amoxicillin $1 \mathrm{~g}$ b.d., Clarithromycin $500 \mathrm{mg}$ b.d. for 14 days $(\mathrm{n}=32)$ D) Same regimen $(O+A+C)-10$ days $(n=46)$, E) Same regimen $(O+$ $A+C)-7$ days $(n=48)$.

Results: H. pylori eradication rates were: in group A, 43\% (56/130), group B, 68\% (99/146), group C, 94\% (30/32), group D, 83\% (38/46) and group E, $81 \%$ (39/48). The most common side effects were diarrhea and taste disturbances. All eradicated patients showed improvement in histology without significant difference, although eradication was statistically higher $(\mathrm{p}<0.02)$ in groups $\mathrm{C}, \mathrm{D}, \mathrm{E}$.

Conclusion: Combination Omeprazole + Amoxicillin had a low effcacy in H. pylori eradication. One week Omeprazole + Amoxicillin + Clarithromycin therapy is enough effective, simple and relatively well tolerated.

\section{A:24 HIGH CURE RATES WITH RANITIDINE BISMUTH CITRATE (PYLORID) PLUS CLARITHROMYCIN GIVEN TWICE DAILY}

K.D. Bardhan ${ }^{1}$, H. Wurzer ${ }^{2}$, M. Marcelino ${ }^{3}$, J. Jahnsen ${ }^{4}$, N. Lotay ${ }^{5}$. ${ }^{1}$ Rotherham General Hospital, Rotherham, UK; ${ }^{2}$ Graz General Hospital, 2. Med. Dept., Graz Austria ${ }^{3}$ Hospital De Sao Marcos, Braga, Portugal; ${ }^{4}$ Medical Department Aker Sykehus, Oslo, Norway; ${ }^{5}$ Glaxo Wellcome $R \& D, U K$

Introduction: H. pylori (Hp) eradication rates were compared for two dual therapies and one triple therapy in this double-blind, randomised, multicentre, parallel group study. Patients received ranitidine bismuth citrate (RBC) $400 \mathrm{mg}$ bd in co-prescription with clarithromycin $500 \mathrm{mg}$ bd (CL bd) or $250 \mathrm{mg}$ qds (CL qds) or clarithromycin $500 \mathrm{mg}$ bd plus metronidazole $400 \mathrm{mg}$ bd (CL + MT) for 14 days, followed by 14 days of RBC 400 mg bd alone to facilitate ulcer healing. Patients and Methods: A total of 646 patients with active DU (634 with confirmed $H p$ infection) entered the study. Patients with healed ulcers were further endoscoped at least 28 days after the end of treatment and $H p$ status was assessed by ${ }^{13} \mathrm{C}$-UBT and histology (Giemsa) on 2 antral and 2 corpus biopsies. Crude (worst case) and observed (evaluable follow-up) intention-to-treat analyses of $H p$ eradication and 4 week DU healing rates were calculated.

Results

\begin{tabular}{llll}
\hline & RBC + CLqds & RBC + CLbd & RBC + CL + MT \\
\hline Eradication (crude), \% (n) & $69(254)$ & $70(252)$ & $70(128)$ \\
Eradication (observed), \% (n) & $84(207)$ & $93 *(190)$ & $92(98)$ \\
Healing (crude), \% (n) & $90(260)$ & $91(257)$ & $85(129)$ \\
Healing (observed), \% (n) & $95(247)$ & $95(243)$ & $92(118)$ \\
Any adverse events, \% & 21 & 26 & 31
\end{tabular}

${ }^{*} \mathrm{p}=0.014$ for comparison with $\mathrm{RBC}+\mathrm{CL}$ qds. $\mathrm{n}=$ number of patients in the analysis.

Conclusion RBC in co-prescription with CL500 mg bd was statistically superior to CL250 mg qds and as effective as triple therapy. All regimens were well tolerated.

\section{A:25 HIGHLY EFFECTIVE TRIPLE THERAPY WITH OMEPRAZOLE, AMOXICILLIN AND CLARITROMYCIN IN PREVIOUS $\boldsymbol{H}$.} PYLORI TREATMENT FAILURES

F. Lerang ${ }^{1}$, B. Moum ${ }^{1}$, J.B. Haug ${ }^{2}$, T. Berge ${ }^{2} .{ }^{1}$ Dept. of medicine, Østfold Central Hospital, Fredrikstad, Norway; ${ }^{2}$ Dept. of microbiology, Østfold Central Hospital, Fredrikstad, Norway

Objectives: To compare cure of $\mathrm{H}$. pylori $(\mathrm{Hp})$ infection of two claritromycin-based triple therapies for 10 days in previous treatment failures.

Methods: Thirty-three patients with duodenal ulcer disease were randomised to 1) omeprazole $20 \mathrm{mg}$ bid, amoxicillin $750 \mathrm{mg}$ bid and claritromycin $250 \mathrm{mg}$ bid (OAC) or 2) bismuth subcitrate $240 \mathrm{mg}$ bid, oxytetracycline $750 \mathrm{mg}$ bid and claritromycin $250 \mathrm{mg}$ bid (BTC). Previous failed regimens included combinations of bismuth, omeprazole, tetracycline, metronidazole, amoxicillin or claritromycin in BTM $(n=22)$, OAM $(n=11), O A(n=7), \operatorname{OCM}(n=2)$ or BCM $(n=1)$. Twenty-eight patients had received one course and five had received three courses. Diagnosis of Hp infection was based on culture with susceptibility testing (E-test) of antrum and corpus biopsy specimens. All but one patient had metronidazole resistant strains and none were resistant to claritromycin or tetracycline.

Results: Cure of $\mathrm{Hp}$ infection was achieved in $18 / 18$ patients (100\%) in OAC and in 8/15 $(53 \%)$ in BTC $(p=0.004)$. Side effects was a minor problem and all patients completed the treatment. The seven patients who failed BTC (with strains still sensitive to claritromycin) have later received $\mathrm{OAC}$ and in 5 of $7 \mathrm{H}$. pylori was eradicated.

Conclusion: Ten-days OAC bid is highly effective and superior to BTC in previous Hp treatment failures. Addition of a proton pump inhibitor to antimicrobials may be critical in second line therapy. The efficacy of OAC after other claritromycin-based therapies needs to be investigated.

\section{A:26 HIGH vS STANDARD DOSE OMEPRAZOLE PLUS AMOXICILLIN FOR TREATMENT OF H. PYLORI POSITIVE DUODENAL ULCER. A MULTICENTRE, NATIONWIDE, RANDOMIZED TRIAL}

G. Maconi, C. Bordi, B. Cesana, F.P. Pilato, I. Damilano, M. Franceschi. Duodenal Ulcer Study Group and Schering-Plough, Italia, Italy

Background. Treatment of $\mathrm{H}$. pylori with an association of omeprazole and amoxicillin gave conflicting results. The causative factors remain still unknown although one of the most important seems to be the dosage of omeprazole.

Aim. Purpose of the present nationwide, multi-center, randomized, single blind study was to compare two omeprazole (OM)-amoxicillin (A) schemes with different doses of omeprazole in the eradication of $\mathrm{H}$. pylori, healing of duodenal ulcer and prevention of duodenal ulcer relapse.

Patients and methods. 322 patients $(229$ males, 93 female; mean age \pm SD: $46.5 \pm 13.1$ yrs) with active H. pylori positive duodenal ulcer were randomly treated with either omeprazole $40 \mathrm{mg}$ bid or $20 \mathrm{mg}$ bid and amoxicillin $500 \mathrm{mg}$ qid over 2 weeks, followed by omeprazole $20 \mathrm{mg}$ om for another 4 weeks. Endoscopic control examination and gastric antral and corpal biopsies for Giemsa staining were performed at the study entry, at the end of treatment, at 2 months and 9 months after termination of treatment.

Results. Duodenal ulcer healing was achieved at the end of treatment in $95.4 \%(149 / 152)$ of patients of OM 80 group and in $95.9 \%$ (144/147) of OM 40 group.

\begin{tabular}{llll}
\hline Treatment & $\begin{array}{l}\text { Hp eradication } \\
\text { at 2 months }\end{array}$ & \multicolumn{2}{l}{ DU relapse at 9 months } \\
\cline { 3 - 4 } & Hp- & Hp+ \\
\hline OM80 + A & $63.6 \%(77 / 121)$ & $1.3 \%(1 / 73)$ & $26.9 \%(14 / 52)$ \\
OM40 + A & $44.5 \%(49 / 110)$ & $7.4 \%(4 / 54)$ & $32.2 \%(20 / 62)$ \\
\hline
\end{tabular}

Table includes all patients who had the appropriate post-Rx visits

H. pylori eradication in the $\mathrm{OM} 80$ group was significantly different from the OM 40 group (p: 0.007).

Conclusion. Efficacy of omeprazole plus amoxicillin gave modest results. However, higher doses of omeprazole seem to be associated with better $\mathrm{Hp}$ eradication rate. We confirm $\mathrm{Hp}$ eradication prevents ulcer relapse.

\section{A:27 BISMUTH, METRONIDAZOLE AND TETRACYCLINE (BMT) \pm ACID SUPPRESSION IN H. PYLORI ERADICATION: A META-ANALYSIS}

N. Chiba, R.H. Hunt. McMaster University, Hamilton, Canada

We performed a meta-analysis of BMT alone or with H2-RA (H2-BMT) or PPI (OBMT-only omeprazole data available).

Methods: Fully recursive search of literature using Medline to July 1995. Included abstracts from 1993-95 meetings: AGA, ACG, BSG, UEGW, WCG and European Hp meetings. Inclusion criteria: adults, prospective studies, per protocol data of number with Hp eradication per number of patients treated, assessed at least $4 \mathrm{wks}$ after end of eradication therapy. Data pooled as mean \% eradication with $95 \% \mathrm{CI}$.

Results: BMT therapy eradicated $81.8 \%$ (78.0-85.6). Eradication rate was not dependent on the daily dosage of metronidazole: $<800 \mathrm{mg} / \mathrm{d}$ (87\%, 82.3-91.7), $1-1.2 \mathrm{~g} / \mathrm{d}(77.2 \%, 70.3-84.1)$ or $1.5-1.6 \mathrm{~g} / \mathrm{d}(82 \%$, 
74.8-89.2) or tetracycline used: $1 \mathrm{~g} / \mathrm{d}(76.5 \%, 67.3-85.7), 1.5 \mathrm{~g} / \mathrm{d}(85.5 \%$, $82.3-88.7)$ or $2 \mathrm{~g} / \mathrm{d}(82 \%, 76.8-87.2)$ as $95 \%$ CI overlapped.

Metronidazole sensitive strains were eradicated in $89.4 \%(313 / 350)$ vs $50.6 \%(81 / 160)$ in resistant (MR) strains. 1 wk data used colloidal bismuth subcitrate (CBS) and not bismuth subsalicylate (BSS). 7-10 d BMT $(82.9 \%, 76.2-89.6)$ is equivalent to $14-15 \mathrm{~d}(80.2 \%, 75.1-85.3)$.

\begin{tabular}{lrrll}
\hline Drugs (arms) & $\mathrm{n}$ & mean $\pm \mathrm{SD}$ & $95 \% \mathrm{CI}$ & \% withdrawn \\
\hline BMT (39) & 2088 & $81.8 \pm 12.2$ & $78.0-85.6$ & 3.4 \\
H2-BMT (13) & 1017 & $89.7 \pm 4.7$ & $87.1-92.3$ & 3.0 \\
OBMT (9) & 567 & $94.8 \pm 6.1$ & $90.8-98.8$ & 3.3 \\
\hline
\end{tabular}

H2-BMT was significantly better than BMT. Higher acid suppression with OBMT gave very consistent results and further significantly increased eradication rates over H2-BMT (95\% CI for the difference $0.3-9.9$ ). Withdrawals due to side effects (when reported) was low. Addition of acid suppression did not decrease drop outs.

Conclusions: Overall mean efficacy of $81.8 \%$ is seen with BMT and MR markedly reduces eradication rate. Significantly higher eradication rate is seen with increasing acid suppression with BMT. Overall withdrawals are low and not affected by addition of acid suppression.

\section{A:28 OMEPRAZOLE ONCE OR TWICE DAILY WITH CLARITHROMYCIN + METRONIDAZOLE IN H. PYLORI ERADICATION: A COHORT STUDY}

N. Chiba, C. Marshall. Surrey GI Clinic, Guelph, Canada

As it is unclear whether omeprazole needs to be given once or twice daily in this promising new triple therapy, our aim was to study this.

Methods: Histology proven Hp positive patients were given 7 days treatment with clarithromycin $250 \mathrm{mg}$ and metronidazole $500 \mathrm{mg}$ bid and allocated to omeprazole $20 \mathrm{mg}$, either once $(O 1 C M)$ or twice $(O 2 C M)$ daily. Side effects and medication compliance assessed at visit 2. Endoscopy with histology (antrum/body) was repeated $>4 \mathrm{wks}$ after pills completed to assess Hp status. Data given as all-patients treated (APT) analysis: includes patients who received at least 1 dose of medication.

Results: Group O1CM: 37 patients: 15 PUD, 15 gastritis, 7 GERD, age 53 y (22-78), m/f 15/22. 2 drop outs. 1 patient took all pills but did not return for final evaluation, included in APT. Eradication seen in $77.1 \%(27 / 35)$ patients. $32 / 35$ took $100 \%$ of pills, two took only half the metronidazole dose by error. $12 / 35$ (34.3\%) patients had no side effects (SE) and 23 patients suffered $48 \mathrm{SE}$ such as loose stools (9), nausea (7), headache (7), gas (4), epigastric pain, dry mouth and taste disturbance (3 each). Only 1 stopped metronidazole due to side effects (perspiring) but completed all other pills. Group O2CM: n = 37: 11 PUD, 22 gastritis, 4 GERD, age 55 y (31-78), $\mathrm{m} / \mathrm{f} 20 / 17$. 1 patient who did not return for the $2^{\text {nd }}$ visit was withdrawn. A further 3 patients completed all pills but refused final evaluation. Thus, APT eradication $77.8 \%(28 / 36)$ and per protocol eradication $84.8 \%$ (28/33). 35 of 36 patients took $100 \%$ of pills. 11 of 36 (30.6\%) had no SE and 25 patients had 52 frequent, minor SE including taste disturbance (13), loose stools (9), nausea (7), headaches (3) and leg tingling (3). No withdrawals occurred due to adverse drug effects.

Conclusions: Eradication rate equivalent whether omeprazole given once or twice daily. Overall eradication of $77 \%$ is lower than reported in the literature. Possible explanations may be $\mathrm{Hp}$ metronidazole resistance (estimated to be $20-30 \%$ in this area), larger doses of clarithromycin may be needed or need longer duration of treatment.

\section{A:29 OMEPRAZOLE PLUS ANTIBIOTICS IN THE ERADICATION OF H. PYLORI INFECTION: A META-REGRESSION}

C.H. Schmid ${ }^{1}$, S.D. Ross ${ }^{2}$, G.W. Whiting ${ }^{2}$, D. Cory ${ }^{1}$, T.C. Chalmers ${ }^{2}$. ${ }^{2}$ MetaWorks Inc., Boston, MA, USA ; ${ }^{1}$ Tufts-NEMC, Boston, MA, USA

Objective: To perform a systematic overview and meta-regression analysis of published studies of omeprazole $(\mathrm{O})$ plus antibiotics $(\mathrm{ab})$ in the treatment of H. pylori (HP) in patients with peptic ulcer disease and non-ulcer dyspepsia.

Methods: All relevant papers and abstracts were retrieved after a comprehensive electronic and manual search, inclusive of all years and all languages, through September, 1995. Inclusion criteria are randomized control trial with $\geq 10$ patients if parallel design, or $\geq 5$ patients if crossover design, with at least one treatment arm containing an orally administered $\mathrm{O}+\mathrm{ab}$ combination of $\geq 5$ days duration. Lead-in intervals for $O>1$ day were excluded, as were studies that did not report testing for HP eradication by treatment arm $\geq 4$ weeks after completion of $a b$ treatment. Probability of HP eradication was calculated for each study arm, and these probabilities were then compared with respect to different risk factors. For multivariate regression analysis, logistic regression based on the binomial outcomes from each study arm were performed, using all risk factors as candidate variables.
Results: 83 studies involving 141 study arms with 5633 patients treated with $\mathrm{O}+\mathrm{ab}(\mathrm{s})$ were identified. Twenty-three (23) different ab regimens were identified, but the vast majority of treatment arms used amoxicillin (A) or clarithromycin $(C)$ or both. Dual therapy $(\mathrm{O}+1 \mathrm{ab})$ was used in 92 treatment arms with 3368 patients; triple therapy $(O+2 a b)$ was used in 45 treatment arms with 1914 patients. HP eradication rates were $65 \%$ for the $O+A$ dual regimens and $76 \%$ for the $O+C$ dual regimens $(p<0.0001)$. Triple therapy eradication rates were $82 \%$ for $\mathrm{O}+\mathrm{A}+\mathrm{C} ; 84 \%$ for $\mathrm{O}+\mathrm{A}+$ imidazole derivatives (M); and $90 \%$ for $\mathrm{O}+\mathrm{C}+\mathrm{M}$. Generally, regardless of the ab combination used, treatment worked better in patients with ulcers than in those without $(p<0.0001)$. Duration of therapy past 1 week does not seem to add any benefit when doses of $\mathrm{O}+\mathrm{ab}$ are high. Higher doses of $\mathrm{O}+\mathrm{C}$ in dual regimens may be equivalent to lower doses of $\mathrm{O}+2 \mathrm{ab}$ in triple regimens. Test-ab and test-maintenance $O$ interactions were seen, and require further studies to understand.

Conclusions: Triple therapy with $\mathrm{O}$ is better than dual therapy with $\mathrm{O}$ in terms of HP eradication rates achieved. In both dual and triple therapies, the higher the $\mathrm{O}$ dose, the higher the HP eradication rates. Further investigation of low dose $\mathrm{O}$ triples vs. high dose duals is recommended, since the results suggest that dual (therapy $\mathrm{O}+1 \mathrm{ab}$ ) for 1 week at high doses may achieve equivalent results to triple therapy $(\mathrm{O}+2 \mathrm{ab})$ at lower doses for longer intervals. This may be important to understand in view of expected differences in compliance and cost.

\section{A:30 THE COST-EFFECTIVENESS OF H. PYLORI ERADICATION WITH DUAL AND TRIPLE THERAPY}

S. Viergutz ${ }^{1}$, P. Malfertheiner ${ }^{2}$, G. Gatz ${ }^{3}$, M. Schlander ${ }^{3}{ }^{1}$ gmi, Munich, Germany; ${ }^{2}$ University of Magdeburg, Germany; ${ }^{3}$ Byk Gulden Pharmaceuticals, Konstanz, Germany

H. pylori $(H p)$ is broadly accepted as a major prerequisite for the development of peptic ulcer disease and its elimination prevents ulcer relapse in the vast majority of patients. This health economic study compares the cost-effectiveness of two extensively tested treatment schemata: a 14 days dual therapy with a proton pump inhibitor (PPI) and amoxycillin, which produced variable cure rates and a 7 days short term triple therapy (i.e. a PPI and two antibiotics), which resulted in very high cure rates.

Methods: Possible therapy courses for $\mathrm{Hp}$-cure were implemented by a decision tree model. The probabilities for the use of a particular course of treatment were determined by a survey of 100 office-based specialists in Germany. The underlying eradication and ulcer relapse rates were analysed by literature research and subsequent meta-analysis. For the analysis, direct costs (medication, diagnostics and consultations with the physicians) were considered.

Results: Taking only the medication costs into account, the daily costs of triple therapy were higher than those of dual therapy. However, the total medication costs of triple therapy were $34 \%$ lower than those of dual therapy. Carrying out a cost-effectiveness analysis, from the point of the German healthcare system, the total costs per year for a patient with successful $H p$-eradication therapy were DEM 1082 with dual and only DEM 657 with triple therapy. The robustness of this result was validated by several sensitivity analyses.

Conclusion: This health economic analysis showed that triple therapy is not only more effective but also more efficient than dual therapy.

\section{A:31 COMPARISON OF TWO ALTERNATIVE STRATEGIES FOR THE MANAGEMENT OF DUODENAL ULCER: AN ECONOMIC MODEL}

X. Lenne ${ }^{1}$, T. Lebrun ${ }^{1}$, B. Requin ${ }^{1}$, M.A. Bigard ${ }^{2}$, R. Colin ${ }^{3}$, A. Cortot $^{4}$, P. Zeitoun ${ }^{5} .{ }^{1}$ CRESGE (LABORES URA CNRS 362), France; ${ }^{2}$ Nancy, France; ${ }^{3}$ Rouen, France; ${ }^{4}$ Lille, France; ${ }^{5}$ Reims, France

This study aimed to compare 2 strategies for the management of duodenal ulcer 5 years after diagnosis with or without Helicobacter pylori eradication.

Methods: A cost-effectiveness (C/E) and cost-benefit (C/B) analysis were performed using simulated Markovian modelling on 100,000 individuals. Revelant clinical data introduced to the model were obtained from published data or from a consensus of experts. The $\mathrm{C} / \mathrm{E}$ analysis evaluated the cost of one additional unit of efficacy, either the number of patients healed after the initial 4 week treatment without recurrence at time $t$, or the mean number of months before the first recurrence. The $\mathrm{C} / \mathrm{B}$ analysis (from a collectivity point of view) evaluated the costs avoided per French Franc (FF) invested. The costs taken into account were the costs of treatment $\left(\mathrm{H}_{2}\right.$ antagonists for the no eradication strategy, omeprazole plus two antibiotics, followed in case of failure by $\mathrm{H}_{2}$ antagonists in eradication strategy), the cost of medical visits and the costs of gastroscopy. A sensitivity analysis was carried out to evaluate the effect of variations in clinical probabilities and costs, eg gastroscopy. The results presented are those where the strat- 
egy without eradication has a maximal efficacy (max) (recurrence without maintenance treatment: $50 \%$ within 2 years; with maintenance treatment: $17 \%$ within 2 years) and the treatment with eradication a minimal efficacy (min) (eradication: $55 \%$ ) and maximal efficacy ( $\max$ ) (eradication: $95 \%$ ).

Results: 5-year figures:

\begin{tabular}{llll}
\hline & & Hyp. 1** & Hyp. 2** \\
\hline Cost-effectiveness ratio* & Erad (max eff)/AH2 (max eff) & $1048 \mathrm{FF}$ & $1375 \mathrm{FF}$ \\
& Erad (min eff)/AH2 (max eff) & $3006 \mathrm{FF}$ & $3944 \mathrm{FF}$ \\
Cost-benefit ratio*** & Erad (max eff)/AH2 (max eff) & $-5.28 \mathrm{FF}$ & $-5.16 \mathrm{FF}$ \\
& Erad (min eff)/AH2 (max eff) & $-0.51 \mathrm{FF}$ & $-0.32 \mathrm{FF}$ \\
\hline
\end{tabular}

*patient without recurrence; ${ }^{* *}$ depending on the mean cost of gastroscopy; ${ }^{* * *}$ Cost reduction per $1 \mathrm{FF}$ invested.

Conclusion: The results support the eradication strategy option with maximal success of eradication as confirmed currently by triple drug regimens. This strategy gives a 5-year benefit of more than $5 \mathrm{FF}$ for each franc invested $(1 \$=4.90 \mathrm{FF})$.

\section{A:32 ONE-WEEK MODIFIED TRIPLE VS TWO-WEEKS DUAL THERAPY WITH PANTOPRAZOLE FOR CURE OF H. PYLORI INFECTION}

R.J. Adamek ${ }^{1}$, T. Bethke ${ }^{2}$ and the International Pantoprazole Helicobacter Pylori (HP) Study Group. ' St. Josef-Hospital, Ruhr-University, Bochum, Germany; ${ }^{2}$ Clinical Research, Byk Gulden, Konstanz, Germany

In this prospective, randomized, multicenter study, one-week modified triple therapy (MTT) with the proton pump inhibitor (PPI) pantoprazole (PAN), clarithromycin (CLA) and metronidazole (MET) was directly compared to a two-week dual therapy (DT) of PPI and CLA with respect to HP eradication. 286 patients with duodenal ulcer (DU) and positive rapid urease test were included in 27 centers in D, A and CH. Patients were randomly treated either with $40 \mathrm{mg}$ PAN bid, $500 \mathrm{mg}$ CLA tid and 500 mg MET tid for one week ( $n=125,42$ female, median age: 48 yrs) or a two-week course of $40 \mathrm{mg}$ PAN bid and $500 \mathrm{mg}$ CLA tid ( $\mathrm{n}=131,47$ female, median age: $48 \mathrm{yrs}$ ) followed by $40 \mathrm{mg}$ PAN od until day 28 . DU healing was assessed endoscopically after 4 weeks. Cure of HP infection was evaluated by ${ }^{13} \mathrm{C}$-urea breath test $\left({ }^{13} \mathrm{C}\right.$-UBT 4 weeks after cessation of PAN therapy. 30 patients (MTT: 17, DT: 13) were excluded from the eradication analysis due to protocol violation e.g. negative ${ }^{13} \mathrm{C}$-UBT at entry or test failures. Seven study discontinuations (MTT: 3; DT: 4) due to likely treatment related adverse events (AE) were included in the evaluation as eradication failures. 256 patients with initially confirmed HP infection by ${ }^{13} \mathrm{C}$-UBT were included in the analysis.

\begin{tabular}{lcl}
\hline Results: & Eradication rate & DU healing \\
\hline PAN-MTT & $119 / 125(95 \%)^{*}$ & $127 / 130(98 \%)^{* *}$ \\
PAN-DT & $82 / 131(63 \%)$ & $131 / 138(95 \%)$ \\
\hline
\end{tabular}

$\left({ }^{*} \mathrm{p}<0.001 ;{ }^{* *} \mathrm{p}>0.05\right.$ Cochran-Mantel-Haenszel test.)

Most common treatment related AE's were taste disturbance (MTT: 12; DT: 14), diarrhoea (MTT: 11; DT: 4) and increase in liver enzymes (MTT: 6; DT: 4). One-week MTT of PAN, CLA and MET is significantly superior to two-week DT with PAN and CLA in curing HP infection. Both treatments were similarly well tolerated.

\section{A:33 SHORT-COURSE THERAPY WITH AMOXICILLIN-CLARITHROMYCIN TRIPLE FOR 10 DAYS (ACT-10) ERADICATES H. PYLORI AND HEALS DUODENAL} ULCER

H. Wurzer, L. Rodrigo, A. Archambault, T. Rokkas, N. Skandalis, R. Fedorak, F. Bazzoli, H. Hentschel, P. Mora, D. Stamler, F. Megraud. 2 Medizinische Abteilung, LKH Giaz, Auenbrugger 15, 8036 Graz, Austria

The role of Helicobacter pylori (HP) eradication in managing duodenal ulcer (DU) has been established; however, consensus regarding the ideal regimen has not been achieved. This double-blind, multicenter, multicountry study compared the efficacy and safety of clarithromycin (CL) plus omeprazole (OM) versus $\mathrm{CL}+\mathrm{OM}+$ amoxicillin (AM) for HP eradication and DU healing.

HP positive patients with active DU and were randomized to receive either CL $500 \mathrm{mg}$ bid, AM $1000 \mathrm{mg}$ bid, and OM $20 \mathrm{mg}$ qd for 10 days; or CL $500 \mathrm{mg}$ tid and OM $40 \mathrm{mg}$ qd for 14 days. No additional acid suppression followed eradication therapy. HP status was assessed pretreatment and at 4-6 weeks follow-up with culture $(2 \mathrm{~A}, 1 \mathrm{C})$, histology (2A), and ${ }^{13} \mathrm{C}$-UBT. Ulcer healing by endoscopy and change in clinical symptoms were also assessed at 4-6 weeks.

Two hundred sixty seven (267) patients were randomized to 10-day triple therapy $(N=137)$ or 14-day dual therapy $(n=130)$. At follow-up, HP was eradicated from $90.2 \%(120 / 133)$ of patients receiving triple therapy compared with $60.0 \%(72 / 120)$ of patients receiving dual therapy ( $\mathrm{p}<$ 0.001 ) in an all-patients-treated analysis. Ulcer healing was high in both treatment groups: ACT-10,93\%, and dual therapy, 92\%; as was compliance ( $>90 \%$ of patients took $>90 \%$ of medication). Tolerability was similar in both groups and discontinuations due to adverse events were low (ACT-10, $2 / 133$, and dual therapy, 6/120). In patients with active DU, ACT-10 is highly effective in eradicating HP and healing DU.

\section{A:34 INTRAGASTRIC DISTRIBUTION OF HELICOBACTER PYLORI AFTER TREATMENT WITH REGIMENS CONTAINING OMEPRAZOLE}

J.C. Yang ${ }^{1}$, C.K. Yang ${ }^{2}$, C.T. Shun ${ }^{3}$, J.T. Wang ${ }^{1}$, S.C. Lee, T.H. Wang ${ }^{1}$ ${ }^{1}$ Dept of Internal Medicine, National Taiwan University Hospital, Taipei, Taiwan, ROC; ${ }^{2}$ Dept of Clinical Pathology, National Taiwan University Hospital, Taipei, Taiwan, ROC; ${ }^{3}$ Dept of Pathology, National Taiwan University Hospital, Taipei, Taiwan, ROC; Institute of Nuclear Energy Research, Tao Yuan, Taiwan, ROC

Recent reports suggest that omeprazole monotherapy partly suppresses and causes the redistribution of $H$. pylori (Hp) in the stomach. However, the effects of dual therapy and triple therapy containing omeprazole has not been well documented. The aim of this study was to analyze the intragastric distribution of $\mathrm{Hp}$ after treatment with regimens containing omeprazole. Methods: Ninety-eight patients with $\mathrm{Hp}(+)$ duodenal ulcer belonged to: $\operatorname{grA}(n=29)$ received omeprazole $20 \mathrm{mg}$ bid $2 \mathrm{wk}$; grB $(n=34)$ omeprazole $20 \mathrm{mg}$ bid plus amoxicillin $500 \mathrm{mg}$ qid $2 \mathrm{wk}$; grC $(\mathrm{n}=35)$ omeprazole 20 $\mathrm{mg}$ bid 2 wk plus amoxicillin $250 \mathrm{mg}$ and metronidazole $250 \mathrm{mg}$ qid $1 \mathrm{wk}$. All patients received ${ }^{13} \mathrm{C}$ Urea breath test and multiple endoscopic biopsies from antrum and high body before and $4 \approx 6$ weeks after anti-Hp therapy. Five specimens from each site were obtained: two for culture using an improved culture system (sensitivity about $98 \%$ ), one for CLO test, and two for histology. Results: The eradication rate of grA, grB and grC was 0 , $76.5 \%$, and $91.4 \%$, respectively. Totally, 40 patients remained Hp positive after treatment. The percentage of positive detection after treatment was $80 \%$ at antrum, $83 \%$ at body, and $90 \%$ with both sites by histology. These data were $83 \%, 78 \%$ and $85 \%$ by CLO test, and $98 \%, 98 \%, 98 \%$ by improved culture system. Conclusion: The detection rate was much higher and became constant with improved culture system. These data indicated that the difference of sensitivity between different tests may be one of the most important factors responsible for the lower detection rate. The so called "patchy distribution" and "proximal migration from the antrum to body after treatment" may in fact play a minor factor. 